\title{
Abnormal Liver Functions as a Risk Factor for Acute Mesenteric Ischemia
}

\author{
Eol Choi, M.D.*, Suk Kyung Hong, M.D., Ph.D.*, Ji Hee Hwang, M.D ${ }^{\dagger}$ \\ Divisions of *Trauma and Surgical Critical Care and ${ }^{\dagger}$ Pediatric Surgery, Department of Surgery, \\ Asan Medical Center, University of Ulsan College of Medicine, Seoul, Korea
}

Correspondence to:

Suk Kyung Hong, M.D. Ph.D.

Division of Trauma and Surgi-

cal Critical Care, Department of

Surgery, Asan Medical Center,

University of Ulsan College of

Medicine, 88 Olympic-ro 43-gil,

Songpa-gu, Seoul 138-736,

Korea

Tel: +82-2-3010-3510

Fax: +82-2-3010-6701

E-mail: skhong94@amc.seoul.kr
Purpose: Acute mesenteric ischemia (AMI) is a potentially fatal condition resulting from inadequate blood supply to the bowels. The clinical features and prognostic factors of AMI are described to aid physicians in clinical decision making.

Methods: The electronic medical records of 39 patients (19 women, mean age: $65.26 \pm 11.13$ years) who underwent surgery for AMI from 2007 to 2009 were retrospectively collected and analyzed. Clinical variables and laboratory parameters on the day of admission or first day of symptoms were analyzed. The primary outcome of interest was patient survival. Multivariate analysis was performed to identify independent predictive factors associated with poor outcome.

Results: Co-morbidities included hypertension (27/39 patients) and diabetes mellitus (14/39). Most patients (23/39) visited the emergency room for AMI-related symptoms, others (16/39) had their first symptom during an unrelated hospitalization. The mean blood pressure at initial assessment was $93.5 \pm 23.9 \mathrm{mmHg}$ and pulse rate was 101 beats/min. Fever was experienced by $17 / 39$ and shock by $13 / 39$ patients. Patients underwent bowel resection (32/39) or diagnostic laparotomy (7/39). The mean intensive care unit stay was 13 postoperative days and hospital stay, 28.3 days. Twenty-two patients (56.1\%) were discharged with improvement, and 17 patients $(43.9 \%)$ died. Acute renal failure, elevated aspartate aminotransferase (AST), elevated alanine aminotransferase (ALT), abnormal bilirubin, and shock were significantly associated with death by univariate analysis. Elevated AST and ALT were strongly associated with mortality by multivariate analysis with logistic regression.

Conclusion: Abnormal liver function indices may be predictive of poor prognosis among patients with AMI. (J Acute Care Surg 2014;4:79-84)

Key Words: Mesenteric vascular diseases, Liver diseases, Aspartate aminotransferases, Bilirubin, Intensive care units

Received August 22, 2014, Revised September 14, 2014, Accepted September 15, 2014

Copyright $\odot 2014$ by Korean Society of Acute Care Surgery

(c) This is an Open Access article distributed under the terms of the Creative Commons Attribution Non-Commercial License (http://creativecommons.org/licenses/by-nc/3.0) which permits unrestricted non-commercial use, distribution, and reproduction in any medium, provided the original work is properly cited.

ISSN 2288-5862(Print), ISSN 2288-9582(Online)

\section{Introduction}

Acute mesenteric ischemia (AMI) is a potentially fatal condition resulting from inadequate blood supply to the bowels. It is implicated in various conditions, including acute mesenteric thromboembolism, ischemic colitis, and global hypoperfusion. Its clinical presentation varies from a mild and limited form to fulminant transmural bowel necrosis. Patients with AMI face a high mortality rate [1], due to the difficulty in diagnosis and advanced age with multiple associated conditions. Early 
diagnosis and treatment are crucial for better prognosis [2]. To identify patients who require prompt and aggressive evaluation, clinicians must understand the characteristics and predictive factors for poor outcome of AMI. The objective of this study was to identify predictive factors for poor outcome in patients with AMI who require surgical resection, in order to aid physicians in clinical decision making.

\section{Methods}

The electronic medical records of 39 patients who underwent surgery for AMI at Asan Medical Center (Seoul, Korea) from 2007 to 2009 were retrospectively analyzed. Patients with a mechanical condition (e.g., strangulation of the bowel) responsible for the bowel ischemia were excluded from the study. Clinical variables, including age, sex, past medical history, symptoms, signs, and hemodynamics, and laboratory parameters obtained on the day of admission or on the first day of symptoms were analyzed. To identify significant predictive factors, the clinical status (including presence of shock, acute renal failure [ARF], and other organ failure) when the first symptom developed was also analyzed. Operative findings, including etiology of AMI, surgical procedure, and location of mesenteric ischemia, were recorded.

ARF was defined as serum creatinine $>1.8 \mathrm{mg} / \mathrm{dl}$ or urine output $<0.5 \mathrm{ml} / \mathrm{kg} / \mathrm{h}$. Shock was defined as a mean blood pressure $(\mathrm{MBP})<65 \mathrm{mmHg}$ or use of a vasopressor to maintain tissue perfusion. Fever was defined as a body temperature $>37.2^{\circ} \mathrm{C}$.

Data are presented as means \pm standard deviations or numbers with percentages. Statistical analysis was performed with SAS software (version 9.1; SAS Institute Inc., Cary, NC, USA). Patients were divided into two groups (survivors and nonsurvivors), which were compared by univariate analysis. Qualitative variables were compared with two-sided tests at the 5\% significance level and with the chi-square test as applicable. Logistic regression was performed to identify independent factors associated with poor outcome.

\section{Results}

\section{Patients}

The 39 patients included 20 men and 19 women, with a mean age of $65.26 \pm 11.13$ years. Table 1 shows the demographic

Table 1. Characteristics of patients and clinical findings at initial assessment

\begin{tabular}{|c|c|c|c|}
\hline Characteristic & $\begin{array}{l}\text { Survivor } \\
(\mathrm{n}=22)\end{array}$ & $\begin{array}{l}\text { Nonsurvivor } \\
\quad(\mathrm{n}=17)\end{array}$ & $\mathrm{p}$-value \\
\hline Age (y) & $68.64 \pm 10.3$ & $60.8 \pm 10.9$ & NS \\
\hline Men & $11(50.0)$ & $9(52.9)$ & NS \\
\hline \multicolumn{4}{|l|}{ Comorbidities } \\
\hline Hypertension & $15(68.2)$ & $12(70.6)$ & NS \\
\hline Diabetes mellitus & 7 (31.8) & $7(41.2)$ & NS \\
\hline Arrhythmia & $8(36.4)$ & 7 (41.2) & NS \\
\hline Chronic renal failure & $0(0)$ & $3(17.6)$ & NS \\
\hline Heart failure & $3(13.6)$ & $5(29.4)$ & NS \\
\hline Vasculopathy $^{\text {a) }}$ & $7(31.8)$ & $7(41.2)$ & NS \\
\hline Smoking & $4(18.2)$ & $3(17.6)$ & NS \\
\hline \multicolumn{4}{|l|}{ Clinical findings } \\
\hline Inpatient occurrence & $5(22.7)$ & $11(64.7)$ & 0.011 \\
\hline ER visit for symptoms & $17(77.3)$ & $6(58.8)$ & 0.030 \\
\hline Fever $^{c}$ & $7(31.8)$ & $10(58.8)$ & NS \\
\hline Mean BP (mmHg) & $98.3 \pm 22.7$ & $87.4 \pm 24.7$ & NS \\
\hline Pulse rate (beats/min) & $98.1 \pm 22.9$ & $103.6 \pm 27.4$ & NS \\
\hline Shock ${ }^{\text {d) }}$ & 4 (18.1) & $9(52.9)$ & 0.039 \\
\hline Acute renal failure ${ }^{\mathrm{e}}$ & $6(27.3)$ & $11(64.7)$ & 0.026 \\
\hline \multicolumn{4}{|l|}{ Initial laboratory parameters } \\
\hline WBC $\left(\times 10^{3} / \mu \mathrm{l}\right)$ & $14.4 \pm 6.4$ & $17.5 \pm 9.0$ & NS \\
\hline $\mathrm{Hb}(\mathrm{g} / \mathrm{dl})$ & $12.7 \pm 2.3$ & $11.6 \pm 3.3$ & NS \\
\hline BUN (g/dl) & $27.7 \pm 17.5$ & $36.1 \pm 18.6$ & NS \\
\hline Creatinine (mg/dl) & $1.4 \pm 0.9$ & $2.01 \pm 0.9$ & 0.048 \\
\hline AST > $>40 \mathrm{IU} / \mathrm{L}$ & $6(27.3)$ & $14(82.4)$ & 0.001 \\
\hline $\mathrm{ALT}>40 \mathrm{IU} / \mathrm{L}$ & $1(4.6)$ & $9(52.9)$ & 0.001 \\
\hline Bilirubin (mg/dl) & $1.42 \pm 0.9$ & $7.44 \pm 10.1$ & 0.008 \\
\hline PT (INR) & $1.9 \pm 1.0$ & $2.33 \pm 1.24$ & NS \\
\hline aPT'T (s) & $46.6 \pm 21.2$ & $51.66 \pm 40.3$ & NS \\
\hline CRP (mg/dl) & $11.9 \pm 8.7$ & $13.3 \pm 14.4$ & NS \\
\hline
\end{tabular}

Values are presented as mean \pm standard deviation or number (\%). NS: nonsignificant, ER: emergency room, BP: blood pressure, WBC: white blood cells, Hb: hemoglobin, BUN: blood urea nitrogen, AST: aspartate aminotransferase, ALT: alanine aminotransferase, PT: prothrombin time, INR: international normalized ratio, aPTT: activated partial thromboplastin time, CRP: C-reactive protein ${ }^{a)}$ Vascular disease, including artherosclerosis obliterans, coronary heart disease, and cerebral infarction; ${ }^{\text {b) }}$ onset of symptom during hospitalization for another disease; ${ }^{\mathrm{c}}$ body temperature $\geq 37.2^{\circ} \mathrm{C}$, d) mean $\mathrm{BP}<65 \mathrm{mmHg}$ or using inotropics to maintain $\mathrm{BP}$; e) serum creatinine $>1.8 \mathrm{mg} / \mathrm{dl}$ or oliguria $<0.5 \mathrm{ml} / \mathrm{kg} / \mathrm{h}$. 
and clinical characteristics of patients and clinical findings on initial assessment. Patients had various comorbidities, including hypertension (69.2\%), diabetes (35.9\%), arrhythmia (38\%), chronic renal failure (7.7\%), heart failure (20.5\%), and vasculopathy (35.9\%). None of the comorbidities showed significant association with mortality. More than half of the patients (23/39, $58.9 \%$ ) visited the emergency room for their AMI-related symptoms. Others (16/39. 41.1\%) had their first symptom during hospitalization for another illness. In these 16 patients, 6 patients were postoperative state of cardiac surgery. And three patients were postoperative state of surgery for abdominal aortic aneurysm. Two patients were postoperative state of transplantation. One underwent liver transplantation, the other underwent kidney transplantation. Four patients admitted to the hospital due to heart, lung and kidney problem (e.g., acute myocardial infarction, acute respiratory distress syndrome). At the initial assessment, the MBP and pulse rate of patients were $93.5 \pm 23.9 \mathrm{mmHg}$ and $101 \pm 24.6$ beats $/ \mathrm{min}$, respectively. Patients exhibited fever (17/39, 43.6\%), shock (13/39, 33.3\%), and $\operatorname{ARF}(17 / 39,43.6 \%)$. Azotemia and hyperbilirubinemia showed significant associations with mortality.

Table 2. Etiology of acute mesenteric ischemia

\begin{tabular}{lrccc}
\hline & $\begin{array}{c}\text { Total } \\
(\mathrm{n}=39)\end{array}$ & $\begin{array}{c}\text { Survivor } \\
(\mathrm{n}=22)\end{array}$ & $\begin{array}{c}\text { Nonsurvivor } \\
(\mathrm{n}=17)\end{array}$ & p-value \\
\hline SMA obstruction & $13(33.3)$ & $6(27.3)$ & $7(41.2)$ & 0.497 \\
SMV obstruction & $5(12.8)$ & $5(22.7)$ & $0(0)$ & 0.056 \\
NOMI & $21(53.8)$ & $11(50.0)$ & $10(58.8)$ & 0.748 \\
\hline
\end{tabular}

Values are presented as number (\%).

SMA: superior mesenteric artery, SMV: superior mesenteric vein, NOMI: nonocclusive mesenteric ischemia.

Table 3. Location of involved intestine

\begin{tabular}{lcccc}
\hline & $\begin{array}{c}\text { Total } \\
(\mathrm{n}=39)\end{array}$ & $\begin{array}{c}\text { Survivor } \\
(\mathrm{n}=22)\end{array}$ & $\begin{array}{c}\text { Nonsurvivor } \\
(\mathrm{n}=17)\end{array}$ & p-value \\
\hline Right colon & $19(48.7)$ & $9(40.9)$ & $10(58.8)$ & 0.355 \\
Left colon & $20(51.3)$ & $9(40.9)$ & $11(64.7)$ & 0.215 \\
Total colon & $11(28.2)$ & $4(18.2)$ & $7(41.2)$ & 0.164 \\
Small bowel & $16(41.0)$ & $5(22.7)$ & $11(64.7)$ & 0.531 \\
Colon and & $12(30.7)$ & $5(22.7)$ & $7(41.2)$ & 0.307 \\
\multicolumn{1}{c}{ small bowel } & & & & \\
\hline
\end{tabular}

Values are presented as number (\%).
Table 2 shows the etiology of AMI. Superior mesenteric artery (SMA) obstruction, superior mesenteric vein (SMV) obstruction, and nonocclusive mesenteric ischemia (NOMI) were found in $33.3 \%, 12.8 \%$, and $53.8 \%$ of patients, respectively. Cases of AMI with SMV obstruction showed a trend of good prognosis, but the association was not statistically significant. The location of the involved intestine is shown in Table 3. Right colon ischemia was more common (48.7\%) than left colon ischemia. Total colon involvement was found in $28.2 \%(11 / 39)$ of patients, and $30.7 \%(12 / 39)$ of patients had simultaneous small bowel ischemia and right or left colon ischemia. The location of the mesenteric ischemia showed no significant association with mortality.

Regarding the surgical procedure, 32 patients (82.0\%) underwent bowel resection, and seven patients (17.9\%) had diagnostic laparotomy. Among the seven patients, four patients were inoperable because no viable intestine remained, and three patients had SMA thrombosis. These three patients underwent SMA thrombectomy first, after which the bowel viability was checked through a second operation.

The mean intensive care unit stay was $13.0 \pm 14.4$ days after surgery, and the mean hospital stay was $28.3 \pm 26.1$ days. A total of 22 patients $(56.1 \%)$ were discharged with improvement, and 17 patients $(43.9 \%)$ died.

\section{Poor Prognostic Factors}

Comparative analysis revealed no statistically significant

Table 4. Multivariate analysis

\begin{tabular}{lccc}
\hline & Odds ratio & $\begin{array}{c}95 \% \text { confidence } \\
\text { interval }\end{array}$ & p-value \\
\hline Abnormal AST $^{\text {a) }}$ & 7.01 & $1.171 \sim 127.55$ & 0.036 \\
Abnormal ALT $^{\text {b) }}$ & 12.22 & $1.289 \sim 38.209$ & 0.024 \\
Hyperbilirubinemia $^{\text {c) }}$ & 1.237 & $0.820 \sim 1.865$ & 0.311 \\
Shock $^{\text {d) }}$ & 1.324 & $0.104 \sim 16.793$ & 0.829 \\
Occurrence during $_{\quad}$ hospitalization $^{\text {Acute renal failure }}{ }^{\mathrm{e})}$ & 0.773 & $0.070 \sim 8.600$ & 0.834 \\
Acut & 0.499 & $0.041 \sim 6.140$ & 0.587 \\
\hline
\end{tabular}

${ }^{\text {a) }}$ Aspartate aminotransferase (AST) $>40 \mathrm{IU} / \mathrm{L} ;{ }^{\text {b) }}$ alanine aminotransferase (ALT) $>40 \mathrm{IU} / \mathrm{L}$, ${ }^{c)}$ bilirubin $>1.2 \mathrm{mg} / \mathrm{dl}$, ${ }^{\mathrm{d})}$ mean BP $<65 \mathrm{mmHg}$ or use of inotropics to maintain blood pressure, ${ }^{\text {e) }}$ serum creatinine $>1.8 \mathrm{mg} / \mathrm{dl}$ or oliguria $<0.5 \mathrm{ml} / \mathrm{kg} / \mathrm{h}$. 
differences with respect to age, sex, or comorbidities (Table 1). Significant differences were observed between the groups in terms of the clinical presentation of the illness.ARF was more common among nonsurvivors than among survivors (64.7\% vs. $27.3 \%, p=0.026$ ). Patients who had their first symptom during a hospitalization tended to show a poorer outcome $(\mathrm{p}=0.011)$. Shock was more frequently found among nonsurvivors than among survivors $(52.9 \%$ vs. $18.1 \%, \mathrm{p}=0.039)$. Initial analysis of the laboratory parameters revealed significant differences between the survivor and nonsurvivor groups for aspartate aminotransferase (AST) elevation (>40 IU/L; 27.3\% vs. $82.4 \%, \mathrm{p}=0.001$ ) and alanine aminotransferase (ALT) elevation ( $>40 \mathrm{IU} / \mathrm{L} ; 4.6 \%$ vs. $52.9 \%, \mathrm{p}=0.001$ ).

Logistic regression was performed with variables that showed statistical significance in univariate analysis, including ARF, elevated AST, elevated ALT, hyperbilirubinemia, and shock. Elevated AST and ALT were strongly associated with mortality after multivariate analysis (Table 4).

\section{Discussion}

Because of its vague clinical features, AMI is sometimes overlooked. However, if not properly treated, AMI can be a catastrophic surgical illness leading to death. Many cases of sepsis of unknown origin, especially in elderly patients, are determined to be abdominal sepsis [3,4], of which AMI is a major cause. Although the pathophysiology of AMI is well known, the mortality of patients with AMI remains high. Prompt diagnosis and treatment is the best way to improve the outcome. In a recent study, patients whose initial symptom was abdominal pain had a lower mortality than those without abdominal pain [5].

There are various underlying reasons for AMI, including arterial embolus, arterial or venous thrombosis, NOMI, and ischemic colitis $[6,7]$. And each type of ischemic injury requires its own unique plan of management. In general, such plans have been developed on the basis of descriptive studies and clinical experience. So it is to be hoped that future reviews on intestinal ischemia will suggest treatment guidelines.

It is difficult to distinguish the pathology of bowel ischemia initially, especially in cases of mild AMI. Carlson and Madoff [8] recently proposed that ischemic colitis was divided into two groups: true ischemic colitis and colitis that almost certainly is not ischemic. The Authors indicated that the so-called "biopsy- proven ischemic colitis" may not actually be "ischemic". Histologic features of ischemic colitis include lamina propria hemorrhage, hemosiderin- laden macrophages, capillary thrombosis, gland atrophy, granulation tissue with crypt abscesses, and pseudopolyps. Because combinations of these findings are also seen in Crohn's disease and infectious colitis, ischemic colitis is easy to misdiagnose [9-11]. Williams and Wittenberg [12] also threw doubt on the presence of poor blood flow in the so-called "ischemic colitic" colon.

An early form of intestinal ischemia shows similar endoscopic findings with other enteritis types. Erythematous and edematous mucosa, ulcerations, submucosal hemorrhages, petechial bleeding, and sharply defined segments of involvement are known enteroscopic findings of the ischemic bowel $[9,13]$. These nonspecific findings can also be seen in inflammatory and infectious diseases. Therefore, the decision of whether surgical treatment is necessary is not an easy one. In this study, to exclude potentially misdiagnosed bowel ischemia, we included patients with a severe form of bowel ischemia, for whom surgery was necessary for treatment.

Important factors affecting whether to perform surgical intervention include the presence of transmural infarction and the reservoir of the patient to endure the effects of mesenteric ischemia. When mesenteric ischemia progresses to transmural infarction, the clinical course is worsening and irreversible. The ischemia damages the mucosal barrier, which leads to the release of toxic inflammatory mediators systemically. This pathologic condition can lead to systemic inflammation, sepsis, and organ failure. The physical condition of the patient must also be considered in deciding whether to perform surgery. With AMI, respiratory or cardiovascular collapse is a very poor prognostic sign. Risk factors for mortality are hemodynamic instability, organ failure, and old age. The viability of the bowel and host response should also be considered.

The pathophysiology of intestinal ischemia/reperfusion (I/R) injury has been studied extensively. Intestinal ischemia damages the intestinal mucosal barrier and induces systemic infla- 
mmation through the endogenous production of oxygen-derived free radicals, proinflammatory cytokines, and copious nitric oxide (NO) from induced NO synthase (iNOS) [2,14,15]. Bathe et al. [16] observed the elevation of tissue necrosis factor and interleukin (IL)-6 after SMA ligation and reperfusion, respectively, in an animal model. Numerous inflammatory mediators and cytokines, including intracellular adhesion molecule-1 (ICAM-1), nuclear factor $\kappa \mathrm{B}$ (NF- $\kappa \mathrm{B})$, and IL-17 are associated with intestinal I/R injury [17-24]. Ultimately, these cytokines cause remote organ injuries, leading to systemic inflammatory response syndrome and multiple organ dysfunction syndrome.

The liver is particularly vulnerable to the negative consequences of intestinal $\mathrm{I} / \mathrm{R}$, presumably because its vasculature is coupled in series with the intestinal circulation [17,25]. Liver enzymes are well-known parameters of liver injury and are generally accepted as the most sensitive indices of acute hepatic injury. Using arat model, Jing et al. [21] observed significant increases in the mean serum AST (280 400 IU/L) and ALT levels (60 150 IU/L) at 3 hours after 1-hour clamping of the SMA. Yao et al. [26] and Wu et al. [20] also used AST and ALT as parameters of liver injury. The liver enzymes protected the organ from intestinal $I / R$, and they observed significant elevation of AST/ALT after intestinal I/R. When AST/ALT elevation is observed in patients suffering from intestinal ischemia, the physician could easily blame the ischemic liver damage associated with generalized septic shock. However, the liver begins to undergo injury even before the toxic materials elicit septic shock.

In this study, we found a strong association between initially elevated liver enzyme levels and mortality, even after eliminating the influence of septic shock from the multivariate analysis. Abnormal liver function in patients with AMI indicates the presence of intestinal $\mathrm{I} / \mathrm{R}$ injury in addition to generalized organ hypoperfusion due to shock.

Despite progress in our understanding of the pathophysiology [6], AMI continues to have a high mortality rate and remains challenging for surgeons. Early diagnosis and treatment determine the overall outcome. However, the spectrum of disease is very diverse. Therefore, the disease course, including patient mortality, completely depends on the decisions made by the physician. The physician should suspect AMI in the case of sepsis of unknown origin. To make a proper decision, all available information should be considered. Our findings suggest that patients presenting with AMI and elevated hepatic enzymes should be suspected of having a poor outcome.

\section{References}

1. Kassahun WT, Schulz T, Richter O, Hauss J. Unchanged high mortality rates from acute occlusive intestinal ischemia: six year review. Langenbecks Arch Surg 2008;393:163-71.

2. Myers SI, Hernandez R. Oxygen free radical regulation of rat splanchnic blood flow. Surgery 1992;112:347-54.

3. Kluge S, Braune S, Nierhaus A, Wichmann D, Derlin T, Mester J, et al. Diagnostic value of positron emission tomography combined with computed tomography for evaluating patients with septic shock of unknown origin. J Crit Care 2012;27:316.e1-7.

4. Azkárate I, Sebastián R, Cabarcos E, Choperena G, Pascal $\mathrm{M}$, Salas E. A prospective, observational severe sepsis/septic shock registry in a tertiary hospital in the province of Guipuzcoa (Spain). Med Intensiva 2012;36:250-6.

5. Acosta-Merida MA, Marchena-Gomez J, Hemmersbach-Miller M, Roque-Castellano C, Hernandez-Romero JM. Identification of risk factors for perioperative mortality in acute mesenteric ischemia. World J Surg 2006;30:1579-85.

6. Brandt LJ, Boley SJ. AGA technical review on intestinal ischemia. American Gastrointestinal Association. Gastroenterology 2000;118:954-68.

7. Renner P, Kienle K, Dahlke MH, Heiss P, Pfister K, Stroszczynski C, et al. Intestinal ischemia: current treatment concepts. Langenbecks Arch Surg 2011;396:3-11.

8. Carlson RM, Madoff RD. Is "ischemic" colitis ischemic? Dis Colon Rectum 2011;54:370-3.

9. Zou X, Cao J, Yao Y, Liu W, Chen L. Endoscopic findings and clinicopathologic characteristics of ischemic colitis: a report of 85 cases. Dig Dis Sci 2009;54:2009-15.

10. Grübel P, Choi Y, Schneider D, Knox TA, Cave DR. Severe isolated Crohn's-like disease of the gastroduodenal tract. Dig Dis Sci 2003;48:1360-5.

11. Lucas W, Schroy PC 3rd. Reversible ischemic colitis in a high endurance athlete. Am J Gastroenterol 1998;93:2231-4.

12. Williams LF Jr, Wittenberg J. Ischemic colitis: an useful clinical diagnosis, but is it ischemic? Ann Surg 1975;182:439-48.

13. Greenwald DA, Brandt LJ. Colonic ischemia. J Clin Gastroenterol 1998;27:122-8.

14. Kawamoto S, Tashiro S, Miyauchi Y, Inoue M. Changes in circulatory status and transport function of the liver induced by reactive oxygen species. Am J Physiol 1995;268:G47-53.

15. Naito $Y$, Takagi $T$, Ichikawa $H$, Tomatsuri N, Kuroda M, Isozaki $\mathrm{Y}$, et al. A novel potent inhibitor of inducible nitric 
oxide inhibitor, ONO-1714, reduces intestinal ischemia-reperfusion injury in rats. Nitric Oxide 2004;10:170-7.

16. Bathe OF, Chow AW, Phang PT. Splanchnic origin of cytokines in a porcine model of mesenteric ischemia-reperfusion. Surgery 1998;123:79-88.

17. Horie Y, Ishii H. Liver dysfunction elicited by gut ischemia-reperfusion. Pathophysiology 2001;8:11-20.

18. Mallick IH, Yang W, Winslet MC, Seifalian AM. Ischemia-reperfusion injury of the intestine and protective strategies against injury. Dig Dis Sci 2004;49:1359-77.

19. Yao JH, Li YH, Wang ZZ, Zhang XS, Wang YZ, Yuan JC, et al. Proteasome inhibitor lactacystin ablates liver injury induced by intestinal ischaemia-reperfusion. Clin Exp Pharmacol Physiol 2007;34:1102-8.

20. Wu C, Xia Y, Wang P, Lu L, Zhang F. Triptolide protects mice from ischemia/reperfusion injury by inhibition of IL-17 production. Int Immunopharmacol 2011;11:1564-72.

21. Jing $H$, Shen $G$, Wang $G$, Zhang F, Li Y, Luo F, et al. MG132 alleviates liver injury induced by intestinal ische$\mathrm{mia} /$ reperfusion in rats: involvement of the AhR and NF $\kappa \mathrm{B}$ pathways. J Surg Res 2012;176:63-73.
22. Leister I, Mbachu EM, Post S, Samel ST, Stojanovic T, Gutt $\mathrm{CN}$, et al. Vasoactive intestinal polypeptide and gastrin-releasing peptide attenuate hepatic microvasculatory disturbances following intestinal ischemia and reperfusion. Digestion 2002; 66:186-92.

23. Kaplan N, Yagmurdur H, Kilinc K, Baltaci B, Tezel S. The protective effects of intravenous anesthetics and verapamil in gut ischemia/reperfusion-induced liver injury. Anesth Analg 2007;105:1371-8.

24. Horie Y, Wolf R, Anderson DC, Granger DN. Hepatic leukostasis and hypoxic stress in adhesion molecule-deficient mice after gut ischemia/reperfusion. J Clin Invest 1997;99: 781-8.

25. Horie Y, Wolf R, Miyasaka M, Anderson DC, Granger DN. Leukocyte adhesion and hepatic microvascular responses to intestinal ischemia/reperfusion in rats. Gastroenterology 1996; 111:666-73.

26. Yao JH, Zhang XS, Zheng SS, Li YH, Wang LM, Wang ZZ, et al. Prophylaxis with carnosol attenuates liver injury induced by intestinal ischemia/reperfusion. World J Gastroenterol 2009;15:3240-5. 